\title{
El kiswahili y el español en una encrucijada lingüística en Kenya
}

\author{
Jane Nzisa Muasya
}

\section{Introducción}

La agrupación de lenguas morfológica y genéticamente supone un avance importante en la lingüística, pero a la vez este paso conlleva un peligro: de hacer tanto hincapié a las diferencias podemos olvidarnos del hecho de que en esencia todas las lenguas humanas son idénticas (Chomsky 1972). "Cada lengua es un sistema que puede cumplir perfectamente la función para la que ha sido creado: la comunicación. Y esta función, sea entre los vecinos de un barrio o internacional, puede ser realizada por cualquier lengua; son los factores económicos, políticos, sociales, culturales, etc., los que determinan que una lengua sea usada internacionalmente y otra tenga una base territorial restringida, pero cualquier lengua hablada en el lugar más recóndito de la Tierra podría ser utilizada como medio de comunicación internacional si se pusiesen los medios para ello" (Junyent 1993: 15-16).

Luego, cada lengua está hecha o se hace a la medida de la cultura correspondiente. Gregersen resume los postulados básicos de la teoría general del lenguaje de forma admirable: "Not only is the word stock of every language considerable and apparently adequate for the culture it is used in, but the vocabularies of all languages share certain universal characteristics. For example, there are always words to express the notions of true or false and hence every language is able to handle the basic concepts of prepositional logic. All languages have words for dealing with time, space, and number. Personal pronouns constitute a linguistic universal; without exception they have at least three persons (e.g. I, you, he) and two numbers (singular and plural). Kinship terms and proper names are universally present categories. At least some parts of the vocabulary (...) are tabooed or avoided with euphemisms everywhere. Idioms and metaphors can be found in all languages. And it may be added that a small number of words everywhere tend even to have similar forms-not only imitative, onomatopoetic words on the order of cuckoo, but also kinship terms such as mama, papa, and a few other items like $m e^{\prime \prime}$ (Gregersen 1977: 11).

Esta cercanía de lenguas tan distintas y a la vez tan distantes la una de la otra geográficamente, es lo que experimenta el hablante del kiswahili cuando se plantea aprender la lengua española. Se encuentra con una grata sorpresa al descubrir que algunas palabras que ya conoce son también españolas, o por lo menos, tienen una pronunciación y significado parecido. Es decir, existen cognados. A continuación ofrecemos algunos ejemplos:

\begin{tabular}{|l|l|l|l|}
\hline kiswahili & español & kiswahili & español \\
\hline Kabila & cabila & kofia & cofia \\
\hline Mnara & alminar & Soko & zoco \\
\hline Sukari & azúcar & Kanuni & canon \\
\hline Shali & chal & Fulani & fulano \\
\hline
\end{tabular}


El paso siguiente es asombrarse de cómo se ha dado tal coincidencia, dado que Kenia no fue colonia española sino inglesa. Además, la historia no sugiere que haya habido ningún contacto entre las dos comunidades lingüísticas. Es más, los españoles no colonizaron ningún país en el África oriental. Es cierto que cuando se habla de lenguas en contacto, se consideran lenguas que se ponen en contacto de modo directo a través de sus hablantes, y esas lenguas pueden llegar a compartir un léxico. Las lenguas emparentadas como es lógico, comparten un léxico.

¿Es posible que dos lenguas tan distintas tengan un léxico común sin que haya habido contacto directo entre sus hablantes y como consecuencia entre las dos? Debe haber un pueblo intermedio. En el estudio presente que es solamente prelimiar, nos proponemos explotar otro contacto que creemos ha sido responsable de poner el kiswahili y el español en una encrucijada lingüística en Kenia, y por extensión en el litoral de África oriental. Dado que las palabras que hemos mencionado anteriormente son también árabes, ¿Podría ser la conexión el árabe?

\subsection{El enlace árabe}

Es cierto que los hablantes del kiswahili como los españoles fueron dominados por personas del mismo habla, aunque esto sí, en distintos tiempos. Somos conscientes de que los conquistadores de España no fueron sólo árabes, y es más acertado hacer referencia a hablantes del árabe. En cambio, los que se apoderaron de la costa de África oriental fueron claramente árabes. Nos parece muy probable que la lengua árabe haya contribuido para proveer a las dos lenguas de un léxico común.

\section{Metodología}

Iniciaremos nuestro estudio con un breve repaso histórico para establecer cómo y cuándo se pusieron en contacto los hablantes del árabe con los españoles por una parte, y con las comunidades de habla kiswahili en el litoral de África oriental por otra. ¿Cuál fue el impacto de este contacto en la comunidad localizada en Africa oriental y en la española, y en las lenguas respectivas? Luego elaboraremos un elenco del lexico kiswahili-espanol-arabe con las definiciones correspondientes según esta bibliografía: Diccionario de la Lengua Española, A Standard Swahili-English Dictionary, A Concise English-Swahili Dictionary, Kamusi ya Kiswahili Sanifu y Taathira ya Kiarabu Pamoja na Kamusi Thulathiya. Examinaremos cómo el kiswahili y el español han acogido los prestamos, es decir ¿Cómo los han adaptado para que encajen en la morfología de las lenguas respectivas? Finalizaremos el estudio con algunas observaciones.

\section{Presencia de hablantes del árabe en España}

“Los árabes permanecieron en España durante casi ocho siglos, desde 711 a 1492, para ser exactos: y durante la mayor parte de este largo período, y a pesar de las repetidas guerras internas y convulsiones, España fue, con mucho, el país más avanzado de Europa, y puente cultural entre ésta, Asia y África. Fue crisol de diferentes pueblos: romanos, visigodos, beréberes, árabes, judíos, y otros muchos; y en su edad de oro, al-Andalus (nombre dado a la península Ibérica por los árabes) fue uno de los más importantes centros intelectuales, tuvo muchas instituciones educacionales, bibliotecas, magníficos palacios y mezquitas, baños públicos, y hermosos jardines" (Chejne 1980: 9-10). 
Es lógico esperar que la convivencia entre los dos pueblos diera y de hecho dio lugar a una nueva cultura, de forma que se puede decir que con la conquista de España "dos sociedades con diferentes caracteres étnicos, lingüísticos, religiosos y culturales se unieron y lograron forjar con éxito una nueva civilización" (Chejne 1980: 20). Al hablar de España, incluimos también el norte de África, ya que hasta ahí llegaba el dominio árabe, y con él la difusión del Islam (Okello 2002).

“Mientras perduró el predominio musulmán, prosperaron el interés en el lenguaje y el proceso de arabización, alcanzando su punto álgido en los siglos X y XI. Sin embargo, ambos declinaron gradualmente con los avances de la reconquista a partir del 1085. Aunque el árabe y su estudio aún tuvieron algunos defensores de talento, su influencia sobre la población andaluza disminuyó drásticamente ya a partir del siglo XIII y, excepto en el reino de Granada, el árabe dejó de ser la lengua de la diplomacia y la cultura. Aún perduró algún tiempo en su forma oral, pero tuvo que competir con las lenguas nacionales de la península, que aumentaban rápidamente en importancia, habladas y escritas" (Chejne 1980: 174).

A la par, se llevaban a cabo iniciativas para que el pueblo español se pudiera liberar de la ligadura al árabe en lo tocante a la religión, las costumbres, y todo aquello que había podido adquirir durante la era de la conquista que se valorara como negativo. De modo que la nueva civilización a la que hemos aludido anteriormente pasaría a ser historia. Sin embargo, no sería justo negar el impacto de dichos años en la historia de España. El influjo árabe se dejó plasmado entre otros en la arquitectura, las costumbres, el arte, la música, la literatura, y sobre todo en la lengua.

“En relación con esto, una gran cantidad de expresiones árabes fueron absorbidas por el español para cubrir una amplia gama de términos en las ciencias, literatura, asuntos militares, administración, comercio, industria, productos y medicamentos, arte y arquitectura, agricultura, etc. Generalmente, la mayoría de las palabras de origen árabe empiezan con al, que corresponde al artículo determinado árabe"(Chejne 1980: 175).

Entre los hablantes del árabe que conquistaron España se encontraban los beréberes y árabes procedentes de Damasco. Mientras éstos se ocupaban de España, sus hermanos de Omán preparaban otro reinado en otra zona de África, concretamente el litoral de África oriental. Parece que no hubo ningún contacto entre los dos grupos de habla árabe, pero nos imaginamos que ambos transmitirían la misma cultura, la misma lengua etc.

\subsection{Presencia árabe en el litoral de África oriental}

"Written accounts and other non-linguistic evidence make it incontrovertible that Arabic speakers have long been along the coast for a thousand years, and probably since the early $1^{\text {st }}$ millennium A.D. Further, although we lack direct written evidence about Persians, it is also very likely that they were along the coast up to the late $1^{\text {st }}$ millennium A.D., as Persia was the major trading force in southern Arabia until its influence was supplanted by Arabs at that time" (Nurse y Hinnebusch 1993: 331). 
Se puede trazar el primer contacto de los árabes con el litoral de África oriental al primer siglo de nuestra era (Polomé 1967; Okello 2002). Este contacto fue por motivos comerciales. Lo curioso es que a pesar del contacto de Persia con la costa, muchos préstamos léxicos de origen persa han sido introducidos al kiswahili por medio del árabe o algunas lenguas de la India, y esto siglos más tarde (Nurse y Hinnebusch 1993). Cuando los árabes formalmente se apoderan del litoral de África oriental es hacia el siglo XVII. Si hasta entonces su presencia se hacía notar aunque veladamente en la arquitectura, en la religión, en la lengua, en adelante casi se impondría. De hecho son pocos los préstamos léxicos tanto persas como árabes que se introdujeron al kiswahili en los siglos anteriores.

"The majority of words in Swahili taken from Arabic are relatively recent and most likely derive from the recent Omani period of influence on the coast, which started with the departure of the Portuguese in the seventeenth century. The reason for this thinking are twofold: Among [sic] this loan-set there are a number of items specific to Omani among the Arabic dialects; and the semantics and the phonological shape of the Swahili item and the Omani source are often identical (allowing for the phonological or morphological modification from Arabic to Swahili)" (Nurse y Hinnebusch 1993: 315).

Lo mismo que hemos dicho del pueblo español puede decirse del pueblo del litoral de África oriental: se da la fusión de dos culturas, una árabe y otra africana, formándose así una nueva civilización: “The coastal civilization was something unique, neither wholly Arab nor exclusively African, eclectic but not cosmopolitan. In Swahili, civilization is spoken of as ustaarabu, being like an Arab. Until the late eighteenth and early nineteenth centuries the immigrants, absorbed in trade, had their faces turned towards the homelands to which they exported goods, just as their religion turned their faces to Mecca. They were essentially trading communities, and were contented to let the trade of the interior flow to them. It is only about 1780 that the first traders seem to have gone inland" (Freeman-Grenville 1971: 168).

Donde más se notó el influjo árabe fue en la religión y en la lengua kiswahili. "Education also flourished at the coast during this time. Koranic schools were built where reading of the Koran was taught. It was not only the Koran that was taught, but other subjects like history, music, poetry and Arab literature. Arab culture was also accepted wholesale. All the coastal peoples began to wear caps, turbans and sandals like the Arabs" (Okello 2002: 21-22). El contacto árabe beneficio la costa también en lo referente a la economia, la politica, y socialmente. El desarrollo fue tal que cuando los portugueses llegaron allí creyeron estar en la Arabia Saudi (Okello 2002). "According to the Kitab al-Zanuj, there were a number of pre-Islamic Arab settlements along the coast, beginning at Mogadishu and ending at Kilwa. They accepted Islam, and the coast became Muslim in the seventh century under Khalifa Omar ibn alKhattab" (Mathew 1971: 102). En lo referente a la lengua, por entonces el kiswahili no se había estandarizado, así que nos referimos a los dialectos del kiswahili, esto es, kimvita, kiamu, kiunguja etc. 
"Until the early $20^{\text {th }}$, or late $19^{\text {th }}$, centuries, the majority of Swahili speakers were first-language speakers of one or another of the coastal dialects. Up to that point, coastal norms were considerably affected by the prestige of Arabic. Although Arabic speakers were relatively few, and although Omani presence was a relatively new phenomenon, Arabic influence was omnipresent in matters of religion, trade, politics, and culture. All that has changed in the $20^{\text {th }}$ century. The majority of Swahili speakers are now second-language, non-coastal, people who do not acknowledge Arabic norms. Political power and language policy are exercised by local governments which are naturally involved with national and African goals" (Nurse y Hinnebusch 1993: 321322).

El área de aportación que interesa para nuestro estudio es de índole lingüística. Naturalmente, las dos lenguas, el kiswahili y el español, se han dejado influir de maneras distintas como podemos imaginar, por ser las necesidades de cada pueblo distintas. Es cierto también que los mismos lexemas en algunos casos han ido adquiriendo, a lo largo del tiempo, usos que actualmente distan del significado original de la palabra en árabe, y otros han caído en desuso.

\section{Resultado}

A continuación haremos un esbozo del léxico de origen árabe que comparte el kiswahili con el español. Incluiremos una transcripción fonémica de los lexemas árabes así como la definición, y señalaremos los casos en que se de una acepción distinta de la original. No pretendemos hacer un diccionario, así que no debe extrañar que no incluyamos todas las acepciones de cada entrada. Para facilitar la consulta y hacerla mas amena, dispondremos los elementos en orden alfabético. Incluiremos una parte de la lista que servirá como una muestra y el resto se podrá consultar en el apéndice al final del estudio.

\subsection{Préstamos de origen árabe}

\begin{tabular}{|l|l|l|}
\hline Lexema kiswahil y definición & Lexema español y definición & Lexema árabe y definición \\
\hline Adesi (N) lentejas & $\begin{array}{l}\text { Adaza (N) zahína, planta y } \\
\text { semilla }\end{array}$ & / adasa/ (N) lenteja \\
\hline $\begin{array}{l}\text { Admeri (N) jefe supremo del } \\
\text { ejército de marinos }\end{array}$ & $\begin{array}{l}\text { Almiral/almirante (N) El que en } \\
\text { las cosas de mar tenía } \\
\text { jurisdicción con mero mixto } \\
\text { imperio y con mando absoluto } \\
\text { sobre las armadas, navíos y } \\
\text { galeras }\end{array}$ & ejefe supremo del \\
\hline Afya (N) la salud & $\begin{array}{l}\text { Alafia (N) fam. Gracia, perdón, } \\
\text { misericordia }\end{array}$ & / al-'afiya/ (N) la salud \\
\hline $\begin{array}{l}\text { Aljebra (N) parte de las } \\
\text { matemáticas que emplea } \\
\text { números y letras }\end{array}$ & $\begin{array}{l}\text { álgebra (N) parte de las } \\
\text { matemáticas en la cual las } \\
\text { operaciones aritméticas son } \\
\text { generalizadas empleando } \\
\text { números, letras y signos }\end{array}$ & /al-wabr/ (N) la reducción. \\
\hline $\begin{array}{l}\text { Allah (N) Dios, normalmente en } \\
\text { las fórmulas árabes }\end{array}$ & $\begin{array}{l}\text { Alá (N) Nombre que dan a Dios } \\
\text { los mahometanos y los } \\
\text { cristianos orientales }\end{array}$ & /allah/ (N) Dios \\
\hline
\end{tabular}


14 Jane Nzisa Muasya

\begin{tabular}{|l|l|l|}
\hline $\begin{array}{l}\text { Amin (adv) Voz que se dice al } \\
\text { final de una oración; así sea }\end{array}$ & $\begin{array}{l}\text { Amén (adv) Voz que se dice al } \\
\text { final de una oración: así sea }\end{array}$ & $\begin{array}{l}\text { /'amîn/ (adv) Voz que se dice al } \\
\text { final de una oración: así sea }\end{array}$ \\
\hline Amiri (N) jefe, líder & $\begin{array}{l}\text { Emir (N) príncipe o caudillo } \\
\text { árabe }\end{array}$ & /al-'amîr/ (N) jefe, líder \\
\hline $\begin{array}{l}\text {-Arifu (adj) entendido, culto } \\
\text {-Arifu (vb) informar, esp. por } \\
\text { carta }\end{array}$ & $\begin{array}{l}\text { Alarife (N) arquitecto o maestro } \\
\text { de obras }\end{array}$ & $\begin{array}{l}\text { /al-'arîf/ (N) el maestro, el } \\
\text { entendido, el oficial. }\end{array}$ \\
\hline Askari (N) soldado, guardia & $\begin{array}{l}\text { Áscari (N) soldado de } \\
\text { infantería marroquí }\end{array}$ & /askârî/ (N) soldado \\
\hline Bahari (N) mar, óceano & Baharí (N) halcón peregrino & /bahr/ (N) mar \\
\hline $\begin{array}{l}\text { Baraka (N) bendición, don } \\
\text { carismático }\end{array}$ & $\begin{array}{l}\text { Baraca (N) en Marruecos, don } \\
\text { divino atribuido a los jerifes o } \\
\text { morabitos }\end{array}$ & $\begin{array}{l}\text { /baraka/ (N) bendición, don } \\
\text { carismático }\end{array}$ \\
\hline $\begin{array}{l}\text { Batili (vb) anular, cancelar, } \\
\text { inutilizar }\end{array}$ & $\begin{array}{l}\text { Baldar (vb) impedir o privar una } \\
\text { enfermedad o accidente el uso } \\
\text { de los miembros o de alguno de } \\
\text { ellos }\end{array}$ & /'batâla/ (vb) anular, inutilizar \\
\hline Bilingani (N) berenjena & $\begin{array}{l}\text { Berenjena (N) Planta anual de la } \\
\text { familia de las solanáceas, con } \\
\text { hojas grandes, aovadas con } \\
\text { flores grandes de color morado; } \\
\text { fruto de este árbol }\end{array}$ & /bâdinwân (N) berenjena \\
\hline
\end{tabular}

\subsection{Prestamos de otras fuentes}

Hay otras palabras, como las que citamos a continuación que han sido adoptadas al kiswahili, al español, o al árabe por medio de lenguas distintas. Sin embargo, es fácil darse cuenta de que el cambio sufrido es muy leve, y esto lleva a la conclusión que posiblemente el lexema original es el mismo. Como es lógico, los préstamos léxicos adoptados por el kiswahili provienen de las lenguas de las naciones que estuvieron involucradas en el comercio en la costa de África oriental, esto es, aparte del árabe, el portugués y el persa. El español deriva básicamente del latín vulgar hablado, y ha adoptado algunas palabras del francés y de otras lenguas europeas.

\begin{tabular}{|l|l|l|}
\hline Lexema kiswahili & Lexema español & Lexema en lengua original \\
\hline $\begin{array}{l}\text { Bastola (N) arma de fuego } \\
\text { pequeño que se sujeta y } \\
\text { dispara con una sola mano. } \\
\text { Préstamo árabe de origen } \\
\text { alemán }\end{array}$ & $\begin{array}{l}\text { Pistola (N) arma de fuego, corta } \\
\text { con general semiautomática, } \\
\text { con una sola manta y dispara } \\
\text { alemán }\end{array}$ & Alemán: pistole (N) pistola \\
\hline $\begin{array}{l}\text { Bendera (N) tela que incluye } \\
\text { colores o señal que representa } \\
\text { un país, reino u asociación. } \\
\text { Préstamo portugués }\end{array}$ & $\begin{array}{l}\text { Bandera (N) Lienzo, tafetán u } \\
\text { otra tela, de figura comúnmente } \\
\text { cuadrada o cuadrilonga, que se } \\
\text { emplea como insignia o señal. } \\
\text { Préstamo gótico }\end{array}$ & $\begin{array}{l}\text { Portugués: bandeira (N) } \\
\text { banderaGótico: /bandwo/ (N) } \\
\text { signo, bandera }\end{array}$ \\
\hline
\end{tabular}




\begin{tabular}{|c|c|c|}
\hline $\begin{array}{l}\text { Bomba }(\mathrm{N}) \text { máquina que sirve } \\
\text { para elevar el agua y darle } \\
\text { impulso. Préstamo portugués }\end{array}$ & $\begin{array}{l}\text { Bomba (n) máquina para elevar } \\
\text { el agua u otro líquido y darle } \\
\text { impulso en dirección } \\
\text { determinada. Préstamo latino. }\end{array}$ & Portugués: bomba (N) bomba \\
\hline $\begin{array}{l}\text { Busu (N) beso-Busu (vb) } \\
\text { besar. Préstamo persa }\end{array}$ & $\begin{array}{l}\text { Beso }(\mathrm{N}) \text { acción y efecto de } \\
\text { besar. Préstamo latino }\end{array}$ & $\begin{array}{l}\text { Persa: /bu:sa/ (N) acción y } \\
\text { efecto de besarLatin: /basium/ }\end{array}$ \\
\hline $\begin{array}{l}\text { Kaki (N; adj) tela fuerte de } \\
\text { algodón del color de hierba } \\
\text { seca que se emplea sobre todo } \\
\text { en la confección de } \\
\text { pantalones y americanas, } \\
\text { color de esta tela. Préstamo } \\
\text { persa }\end{array}$ & $\begin{array}{l}\text { Caqui (N; adj) tela de algodón o } \\
\text { de lana, cuyo color varía desde } \\
\text { el amarillo de ocre al verde gris, } \\
\text { color de esta tela. Préstamo } \\
\text { inglés de origen urdú }\end{array}$ & $\begin{array}{l}\text { Urdú y persa: /khâki/ (adj) del } \\
\text { color de polvo }\end{array}$ \\
\hline $\begin{array}{l}\text { Kanuni } \quad(\mathrm{N}) \quad \text { regla } \\
\text { fundamental que prescribe } \\
\text { cómo debe tratarse un asunto. } \\
\text { Préstamo árabe }\end{array}$ & $\begin{array}{l}\text { Canon }(\mathrm{N}) \text { regla o precepto. } \\
\text { Préstamo latino de origen griego }\end{array}$ & $\begin{array}{l}\text { Árabe: /qânûn/ (N) regla, } \\
\text { modelo.Latín: canon }\end{array}$ \\
\hline $\begin{array}{l}\text { Kasha }(\mathrm{N}) \text { especie de } \\
\text { recipiente que sirve para } \\
\text { guardar y transportar cosas. } \\
\text { Préstamo portugués }\end{array}$ & $\begin{array}{l}\text { Caja }(\mathrm{N}) \text { recipiente de materia y } \\
\text { forma variables, que cubierto } \\
\text { con una tapa suelta o unida a la } \\
\text { parte principal, sirve para } \\
\text { guardar o transportar en él } \\
\text { alguna cosa. Préstamo latino }\end{array}$ & $\begin{array}{l}\text { Portugués: caixa } \\
\text { Latín: capsa }\end{array}$ \\
\hline Karafuu (N) clavo & $\begin{array}{l}\text { Clavo }(\mathrm{N}) \text { una especia extraída } \\
\text { de la flor del clavero. Préstamo } \\
\text { latino }\end{array}$ & $\begin{array}{l}\text { Árabe: /qurunfûl/ (N) clavo } \\
\text { Latín: clavus }(\mathrm{N}) \text { clavo }\end{array}$ \\
\hline
\end{tabular}

\section{Reflexión}

Como se ve, nuestro estudio, sin pretender ser exhaustivo, nos ha proporcionado un elenco de parte del léxico que comparte el kiswahili con el español. Se verá que el español en muchos casos ha adoptado los préstamos léxicos junto con el artículo determinado árabe al, por ejemplo, alarife, alberca, alminar, algorfa, alfaraz, y en menor grado encontramos préstamos sin artículo como faquir mozárabe, zoco, mezquita y café. Sin embargo, no quiere decir que el español se sirva del artículo árabe para sustituir el artículo español en estas palabras, sino que lo adopta como si fuera parte constituyente del lexema, y otorga género gramatical al sustantivo en cuestión, y de este modo tenemos el alarife, la alberca, el alminar, el alfaraz la algorfa etc. Se esperaría que al fácilmente se convertiría en $e l$, y que las unidades léxicas serían de género masculino. No es el caso, y de hecho las palabras de origen árabe son tanto de género masculino como femenino como acabamos de ver.

El kiswahili en cambio, por carecer de artículos, adopta los lexemas de ordinario sin artículo, rompe los grupos consonánticos cuando haga falta, y los clasifica en distintas clases nominales según las características de los sustantivos. 
“(..) the integration of arabic loans into Swahili morphology shows remarkable features of a thorough interpretation of the forms along strictly Bantu lines, e.g., wakati 'time' (from Arabic/waqt/ is reanalyzed as a $\{\mathrm{u}\}$ class noun with the /w/ allomorph of the prefix before initial vowel ( $\mathrm{w}$-akati), and accordingly forms its plural according to the pattern of the $\{\mathrm{n}\}$ class nouns, i.e., nyakati; kiriba 'water-skin' (from Arabic /qirba/ ) is reanalyzed as a $\{\mathrm{ki}\}$ class noun (ki-riba), and accordingly appears in the plural with the \{vi\} prefix as viriba; etc" (Polomé 1967: 171).

Entre los lexemas de nuestro elenco, birika, orofa/gorofa y farasi son de la clase $\mathbf{N}$; mnara de la clase M-MI; fukara y kadhi de la clase JI-MA, y mstaarabu de la clase M-WA. Además, a cada sustantivo se le ajudica los concordantes correspondientes de forma que semánticamente mstaarabu, kadhi, fukara y farasi son de la clase M-WA. Encontramos, sin embargo, algunos lexemas que han sido adoptados al kiswahili junto con el artículo, y como ocurre en español, se considera el artículo como parte constituyente del lexema. De estos se puede citar almasi diamante, alasiri por la tarde, alhamisi jueves, askari soldado, guardia, asili origen, naturaleza y arusi boda.

En lo que respeta a los verbos, con nuestra lista limitada sólo hemos encontrado dos verbos que el español comparte con el kiswahili: zalamear y baldar por una parte, y salimia/-salimu y -batili por otra. En general parece que el español ha adoptado un número muy reducido de verbos del árabe, y ha derivado otro número, también reducido, de sustantivos de préstamo árabe y se han hecho a la morfología verbal. Los tres verbos que citamos llevan la terminación -ar y son regulares.

El kiswahili ha sido muy generoso en acoger verbos del árabe y acomodarlos al sistema morfológico verbal. Los dos verbos que hemos citado, -salimu y -batili forman el infinitivo como cualquier verbo bantú, esto es, con el prefijo ku- y una vocal al final. Es decir que se registra una morfología discontinua en el verbo, con esta estructura: marca del infinitivo+lexema verbal+morfema modal. Hay una diferencia sin embargo, y es que los verbos no bantúes llevan morfemas modales peculiares: " "'de ordinario los préstamos verbales (sobre todo los de origen árabe) no necesitan seguir los patrones que se aplican a los verbos bantúes. Nos percatamos de que, por ejemplo, mientras los verbos bantúes terminan en /a/ los verbos prestados terminan en /i/, /E/ y /u/" (Mgullu 2001: 210).

El impacto del árabe se verifica además en la sintaxis: "Swahili, doubtless the most heavily Arabized Sub-Saharan language, has a number of function words of Arabic origin, such as au 'or', wala 'nor', lakini 'but', bila 'without', baada 'after', kabla 'before', ila 'except', kama 'like, as, if', and hata 'until, even'” (Goodman 1971: 669).

El contacto árabe se ha hecho sentir en la fonología de las dos lenguas que estamos examinando. Es lógico que el hecho de acoger una nueva unidad léxica traiga consigo nuevos sonidos o fonemas.

"Among traditional Swahili communities, words originating in Arabic often maintain some features of their Arabic pronunciation, e.g. baxt(i) 'luck' with a consonant cluster and the foreign phoneme $/ x /$. However, as Swahili has spread to non-Arabicised Bantu 
peoples and everyday usage in traditional Swahili communities, certain Bantu processes of nativization have taken place, e.g. bahati with typical Bantu structure and nativisation of $/ x />/ h^{\prime \prime}$ (Wald 2000: 1013).

El sistema fonológico del kiswahili cuenta con cuatro fonemas consonánticos de origen árabe: /ð/, /T/, / /̈/ y /x/. Asimismo, “(...) three dipthongs (/au, ai, ei/), which rarely or never occur in inherited words, have been taken from Arabic, as have numerous consonant clusters, many of which are in the process of being broken up by epenthetic vowels today" (Nurse and Hinnebusch 1993: 312).

\section{Conclusión}

En líneas generales se puede decir que el significado de los préstamos léxicos en kiswahili es más fiel al original árabe, en muchos casos idéntico, si lo comparamos con el español. Además, muchos de los préstamos léxicos han caído en desuso en la lengua española. Esto posiblemente se debe al transcurso del tiempo: la lengua española lleva más tiempo alejada del contacto con el árabe, mientras que el contacto del kiswahili con el árabe es todavía muy reciente y se sigue manteniendo dado que una parte de la población keniana y en general de la costa de África oriental, es de habla árabe.

Como ha pasado en España, la convivencia de las dos culturas en la costa de África oriental ha dejado su huella en la arquitectura, la música, las costumbres y la poesía, entre otros. Ya hemos mencionado en otro momento que el kiswahili al principio se escribió con la escritura árabe. Fijémonos en el influjo ejercido por el contacto del kiswahili con la lengua árabe en la poesía:

"As rhetorical style is expressed in art, Swahili poetry has adopted numerous Arabic metres and the use of vocalic rhyme. Vocalic rhyme is unknown in traditional Bantu verse (in contradistinction to tonal rhyme), but Swahili has used the identity of wordfinal syllables to create a tradition of rhyme schemes far more intricate than in the Arabic source, e.g. the regular form of the Swahili quatrain (four line stanza) has the rhyme scheme ab/ab/ab/bc, which repeats as de/de/de/ec. Note that only the final rhymes of each stanza are related. This typical pattern of stanza rhyme suggests the refrain of a repeated coda line, marking the end of each stanza, commonly used in Bantu and West African song and often in Swahili song as well. This blending of Bantu and non-Bantu traditions is suggestive of more prosaic adaptations of nonBantu rhetorical patterns which remain to be described in Swahili" (Wald 2000: 10131014).

No es nuestra intención averiguar aquí qué áreas en las dos lenguas han sido más afectadas por los préstamos. Una vista rápida de los lexemas compartidos nos indica que la administración y la agricultura han recibido un influjo considerable. En lo referente al kiswahili resumimos el efecto del contacto árabe y la consiguiente adopción de unidades léxicas a continuación: 
"The Arabic loanwords in Swahili belong to all areas of cultural and social life. Most numerous, of course, are the terms pertaining to Islamic religious life, which still pervades all activities in the coastal and island areas. Therefore, the time of the day is mainly marked by the Moslem times of prayer, e.g., 'dawn' is alfajiri (prayer about 4:00 a.m.), 'noon' is adhuhuri (prayer between 12:00 and 2:00 p.m.), 'afternoon' is alasiri (prayer between 3:30 and 4:30 p.m.), etc. Similarly, the days of the week are counted with reference to the Moslem holy day Ijumaa 'Friday', as Jumamosi (with the old Bantu numeral mosi 'one') 'Saturday', Jumapili 'Sunday', Jumatatu 'Monday', Jumanne 'Tuesday', Jumatano 'Wednesday'. 'Thursday', however, is called Alhamisi, with an Arabic name meaning literally 'the fifth', as the Arabs have adhered to the old Oriental time-reckoning which considers the Sabbath as the last day and starts the week on Sunday" (Polomé 1967: 172).

Concluimos que es innegable que el árabe ha ejercido un influjo tanto en el pueblo español y su lengua como en el pueblo de la costa de África oriental y sus lenguas, y que a pesar de la distancia y el tiempo que ha mediado, y que se trate de naciones tan distintas, hay elementos que comparten por haber sido dominados por la misma cultura.

\section{Bibliografía}

Bosha, Ibrahim (1993): Taathira za Kiarabu Katika Kiswahili Pamoja na Kamusi Thulathiya, Dar es Salaam: Dar es Salaam University Press.

Chejne, Anwar G. (1980): Historia de España Musulmana, Madrid: Ediciones Cátedra. Chomsky, Noam (1972) Syntactic Structures, The Hague: Mouton.

Freeman-Grenville, G. (1971): “The Coast 1498-1840” en (eds.) Oliver, Roland y Mathew, Gervase (1971): History of East Africa, Nairobi: Oxford University Press, págs. 129-168.

Gregersen, Edgar (1977): Language in Africa An Introductory Survey, New York: Gordon and Breach Science Publishers Inc.

Inter-territorial Language Committee for the East African Dependencies (ILCEAD) (1975): A standard Swahili-English Dictionary, Nairobi: Oxford University Press.

Junyent, Carme (1993) Las Lenguas del Mundo Barcelona: Ediciones Octaedro.

Mathew, Gervase (1971): "The East African Coast Before the Coming of the Portuguese" en (eds.) OLIVER, Roland y Mathew, Gervase (1971): History of East Africa, Nairobi: Oxford University Press, págs. 94-127.

Mgullu, Richard (2001): Mtalaa wa Isimu, Nairobi: Longhorn Publishers.

Nurse, Derek y Hinnebusch, Thomas (1993): Swahili and Sabaki a Linguistic History, Berkeley: University of California Press.

Okello, Benson (2002): A History of East Africa, Kampala: Fountain Publishers Ltd.

Polomé, Edgar (1967): Swahili Language Handbook, Washington: Centre for Applied Linguistics. 
Real Academia Española (1992): Diccionario de la Lengua Española Madrid ${ }^{21}$ : Editorial Espasa Calpe.

Snoxall, R. A. (1979): A concise English-Swahili Dictionary, Nairobi: Oxford University Press.

Wald, Benji (2000): "Swahili and the Bantu Languages" en (ed.) Comrie, Bernard (2000): The World's Major Languages, New York: Routledge, págs. 991-1014.

\section{Apéndice}

\begin{tabular}{|c|c|c|}
\hline $\begin{array}{l}\text { Birika }(\mathrm{N}) \text { recipiente } \\
\text { grande de metal para } \\
\text { contener agua; jara; } \\
\text { tetera; cisterna }\end{array}$ & $\begin{array}{l}\text { Alberca }(\mathrm{N}) \text { depósito artificial } \\
\text { de agua, con muros de } \\
\text { fábrica, para el riego }\end{array}$ & /al-birka/ el estanque \\
\hline $\begin{array}{l}\text { Dafina }(\mathrm{N}) \text { un tesoro } \\
\text { escondido o un regalo } \\
\text { inesperado }\end{array}$ & $\begin{array}{l}\text { Adafina }(\mathrm{N}) \text { olla que los } \\
\text { hebreos colocan el anochecer } \\
\text { del viernes en un anafe, } \\
\text { cubriéndola con rescoldo y } \\
\text { brasas, para comerla el } \\
\text { sábado. }\end{array}$ & $\begin{array}{l}\text { /adâfina/ (N) la oculta o } \\
\text { encubierta. }\end{array}$ \\
\hline $\begin{array}{l}\text { Daraja }(\mathrm{N}) \text { escalón, } \\
\text { conjunto de escalones; } \\
\text { escalera; puente; nivel o } \\
\text { rango }\end{array}$ & $\begin{array}{l}\text { Adaraja (N) Arq. Cada uno } \\
\text { de los dentellones que se } \\
\text { forman en la interrupción } \\
\text { lateral de un muro para su } \\
\text { trabazón al proseguirlo }\end{array}$ & /a-ddâ rawa/ (N) el escalón \\
\hline $\begin{array}{l}\text { Faida }(\mathrm{N}) \text { beneficio, } \\
\text { ganancia, ventaja }\end{array}$ & $\begin{array}{l}\text { Alfaida }(\mathrm{N}) \text { la crecida del río } \\
\text { por el flujo de la pleamar }\end{array}$ & /al-fa'ida/ (N) \\
\hline $\begin{array}{l}\text { Fakiri/fukara } \\
(\mathrm{N}) \text { mendigo, pobre }\end{array}$ & $\begin{array}{l}\text { Faquir }(\mathrm{N}) \text { santón musulmán } \\
\text { que vive de limosna y } \\
\text { practica actos de singular } \\
\text { austeridad, por ext., asceta } \\
\text { de otras sectas hindúes }\end{array}$ & $\begin{array}{l}\text { /faqîr/ (N) pobre, hombre } \\
\text { religioso que hace voto de } \\
\text { pobreza }\end{array}$ \\
\hline Farasi $(\mathrm{N})$ caballo & $\begin{array}{l}\text { Alfaraz }(\mathrm{N}) \text { caballo que } \\
\text { usaban los árabes para las } \\
\text { tropas ligeras }\end{array}$ & /al-faras/ (N) caballo \\
\hline $\begin{array}{l}\text { Fulani }(\mathrm{N} \text {; adj) Voz con } \\
\text { que se refiere de modo } \\
\text { indefinido a personas o } \\
\text { cosas }\end{array}$ & $\begin{array}{l}\text { Fulano (N) Voz con que se } \\
\text { suple el nombre de una } \\
\text { persona, cuando se ignora o } \\
\text { a propósito no se quiere } \\
\text { expresar }\end{array}$ & /fulân/ (N) un tal \\
\hline
\end{tabular}




\begin{tabular}{|c|c|c|}
\hline $\begin{array}{l}\text { Gharama }(\mathrm{N}) \text { gasto, } \\
\text { coste, impuesto, tasa }\end{array}$ & $\begin{array}{l}\text { Garrama }(\mathrm{N}) \text { cierta } \\
\text { contribución que pagan los } \\
\text { musulmanes a sus príncipes }\end{array}$ & /garâma/ (N) impuesto \\
\hline $\begin{array}{l}\text { Gorofa/orofa }(\mathrm{N}) \text { piso, } \\
\text { edificio, habitación en } \\
\text { la primera planta }\end{array}$ & $\begin{array}{l}\text { Algorfa }(\mathrm{N}) \text { sobrado o } \\
\text { cámara alta, para recoger y } \\
\text { conservar granos }\end{array}$ & $\begin{array}{l}\text { /al-gurfa/ (N) habitación, } \\
\text { cámara }\end{array}$ \\
\hline $\begin{array}{l}\text { Haba }(\mathrm{N}) \text { muy poco en } \\
\text { número, poco }\end{array}$ & $\begin{array}{l}\text { Alfaba (N) Unidad de } \\
\text { tasación de un terreno } \\
\text { basada en el valor en renta } \\
\text { de este y que se utilizó en } \\
\text { los repartimientos de } \\
\text { Murcia en el s. XIII. }\end{array}$ & $\begin{array}{l}\text { /habba/ (N) semilla, grano, } \\
\text { poco }\end{array}$ \\
\hline $\begin{array}{l}\text { Haini }(\mathrm{N}) \text { traidor, } \\
\text { persona engañosa }\end{array}$ & $\begin{array}{l}\text { Zaino (adj) traidor, falso, } \\
\text { poco seguro en el trato }\end{array}$ & $\begin{array}{l}\text { /jâ'in/ }(\mathrm{N}) \text { traidor, persona } \\
\text { engañosa }\end{array}$ \\
\hline Haja $(\mathrm{N})$ necesidad & Alhaja $(\mathrm{N})$ joya & $\begin{array}{l}\text { /al-hâwa/ la cosa necesaria, } \\
\text { el utensilio }\end{array}$ \\
\hline $\begin{array}{l}\text { Hina }(\mathrm{N}) \text { tinte rojo que } \\
\text { se prepara a base del } \\
\text { polvo de las hojas de } \\
\text { una planta -mhina-, y } \\
\text { se emplea para decorar } \\
\text { las manos y los pies } \\
\text { como si fuera un tatuaje }\end{array}$ & $\begin{array}{l}\text { Alheña }(\mathrm{N}) \text { polvo a que se } \\
\text { reducen las hojas de la } \\
\text { alheña cogidas en la } \\
\text { primavera y secadas } \\
\text { después al aire libre. Sirve } \\
\text { para teñir }\end{array}$ & /al-hinnâ'/ (N) el ligustro \\
\hline $\begin{array}{l}\text { Hirizi (N) amuleto, } \\
\text { talismán }\end{array}$ & $\begin{array}{l}\text { Grisgrís (N) especie de } \\
\text { amuleto o nómina } \\
\text { supersticiosa de los } \\
\text { moriscos }\end{array}$ & $\begin{array}{l}\text { /hirz/ (N) amuleto, } \\
\text { talismán }\end{array}$ \\
\hline $\begin{array}{l}\text { Imamu }(N) \text { el que } \\
\text { dirige las oraciones en } \\
\text { una mezquita }\end{array}$ & $\begin{array}{l}\text { Imam }(N) \text { El que está } \\
\text { delante, el que preside, jefe }\end{array}$ & $\begin{array}{l}\text { /'imân/ (N) el que dirige las } \\
\text { oraciones en una mezquita, } \\
\text { jefe, líder }\end{array}$ \\
\hline $\begin{array}{l}\text { Inshallah (interj) } \\
\text { fórmula que se emplea } \\
\text { para expresar un deseo } \\
\text { de que suceda algo }\end{array}$ & $\begin{array}{l}\text { Ojalá (interj) Interjección } \\
\text { con que se denota vivo } \\
\text { deseo de que suceda una } \\
\text { cosa. }\end{array}$ & $\begin{array}{l}\text { /wâsallah/ (interj) y quiera } \\
\text { Dios/inðâ'allâh/ (interj) } \\
\text { fórmula que se emplea para } \\
\text { manifestar asentimiento o } \\
\text { el deseo de que suceda una } \\
\text { cosa }\end{array}$ \\
\hline
\end{tabular}




\begin{tabular}{|c|c|c|}
\hline $\begin{array}{l}\text { Jamaa (N) familia, } \\
\text { sociedad, congregación, } \\
\text { asamblea }\end{array}$ & $\begin{array}{l}\text { Aljama }(\mathrm{N}) \text { junta de moros o } \\
\text { judíos }\end{array}$ & $\begin{array}{l}\text { /wamâ'/ (N) familia, } \\
\text { sociedad, congregación, } \\
\text { asamblea, grupo }\end{array}$ \\
\hline $\begin{array}{l}\text { Kabila }(\mathrm{N}) \text { tribu o } \\
\text { grupo étnico }\end{array}$ & $\begin{array}{l}\text { Cabila }(\mathrm{N}) \text { tribu de beduinos } \\
\text { o de beréberes }\end{array}$ & $\begin{array}{l}\text { /qabîla/ (N) tribu o grupo } \\
\text { étnico }\end{array}$ \\
\hline $\begin{array}{l}\text { Kadhi }(\mathrm{N}) \text { juez de la ley } \\
\text { musulmana }\end{array}$ & $\begin{array}{l}\text { Alcalde }(\mathrm{N}) \text { Presidente del } \\
\text { ayuntamiento de cada } \\
\text { pueblo o término municipal }\end{array}$ & /al-qâdî/ (N) el juez \\
\hline $\begin{array}{l}\text { Kafiri (N) infiel, } \\
\text { pagano, ateo, }\end{array}$ & Cafre (N) fig. Bárbaro y cruel & $\begin{array}{l}\text { /kâfir/ (N) infiel, incrédulo, } \\
\text { persona que no es } \\
\text { musulmana }\end{array}$ \\
\hline Kafuri (N) canfor & $\begin{array}{l}\text { Canfor/alcanfor }(\mathrm{N}) \\
\text { producto de olor penetrante } \\
\text { característico que se obtiene } \\
\text { del alcanforero. }\end{array}$ & /al-qâfûr/ (N) canfor \\
\hline Kahawa $(\mathrm{N})$ café & $\begin{array}{l}\text { Café }(\mathrm{N}) \text { bebida que se hace } \\
\text { por infusión con la semilla } \\
\text { del cafeto, tostada y molida }\end{array}$ & /qahwa/ (N) café \\
\hline $\begin{array}{l}\text { Kalamu (N) lápiz; } \\
\text { pluma }\end{array}$ & $\begin{array}{l}\text { Cálamo }(\mathrm{N}) \text { poét. Pluma de } \\
\text { ave o de metal para escribir. } \\
\text { Préstamo latino }\end{array}$ & /qalam/ (N) lápiz; pluma \\
\hline $\begin{array}{l}\text { Kandili (N) linterna, } \\
\text { lámpara }\end{array}$ & $\begin{array}{l}\text { Candela }(\mathrm{N}) \text { vela de } \\
\text { encender,candelero para } \\
\text { sostener velas,fam. lumbre }\end{array}$ & $\begin{array}{l}\text { /qandîl/ (N) candela, } \\
\text { lámpara }\end{array}$ \\
\hline Kofia $(\mathrm{N})$ gorra & $\begin{array}{l}\text { Cofia }(\mathrm{N}) \text { gorra para sujetar } \\
\text { el pelo. Préstamo latino }\end{array}$ & $\begin{array}{l}\text { /kûfiya/ (N) un paño de } \\
\text { seda para tapar la cabeza }\end{array}$ \\
\hline Limau (N) lima & $\begin{array}{l}\text { Lima }(\mathrm{N}) \text { fruto del limero, } \\
\text { árbol que da la lima }\end{array}$ & /lîma/ (N) lima \\
\hline Mia (N) cien, ciento & $\begin{array}{l}\text { Mía }(\mathrm{N}) \text { en el antiguo } \\
\text { protectorado español de } \\
\text { Marruecos, unidad regular } \\
\text { indígena, dependiente del } \\
\text { Majzén jalifiano, compuesta } \\
\text { de unos cien hombres de } \\
\text { infantería o de otros tantos } \\
\text { de caballería }\end{array}$ & /mi'a/ (N) ciento \\
\hline
\end{tabular}




\begin{tabular}{|c|c|c|}
\hline Mnara (N) torre, el faro & $\begin{array}{l}\text { Alminar (N) Torre de las } \\
\text { mezquitas, por lo común } \\
\text { elevada y poco gruesa, } \\
\text { desde cuya altura convoca } \\
\text { el almuédano a los } \\
\text { mahometanos en las horas } \\
\text { de oración }\end{array}$ & $\begin{array}{l}\text { /al-manâra/ }(\mathrm{N}) \text { torre, el } \\
\text { faro }\end{array}$ \\
\hline $\begin{array}{l}\text { Msikiti }(\mathrm{N}) \text { templo } \mathrm{u} \\
\text { oratorio musulmán }\end{array}$ & $\begin{array}{l}\text { Mezquita }(\mathrm{N}) \text { templo u } \\
\text { oratorio musulmán }\end{array}$ & $\begin{array}{l}\text { /maswid/ }(\mathrm{N}) \text { templo } \mathrm{u} \\
\text { oratorio musulmán }\end{array}$ \\
\hline $\begin{array}{l}\text { Miliki }(\mathrm{N}) \text { propiedad, } \\
\text { posesión, riqueza }\end{array}$ & $\begin{array}{l}\text { Mulquía (N) en Marruecos, } \\
\text { documento autorizado por } \\
\text { testigos, que acredita la } \\
\text { legítima posesión de un } \\
\text { terreno }\end{array}$ & $\begin{array}{l}\text { /milkiwwa/ }(\mathrm{N}) \text { cosa } \\
\text { relativa a la propiedad/ } \\
\text { milk/ (N) propiedad, } \\
\text { posesión, riqueza, fortuna }\end{array}$ \\
\hline $\begin{array}{l}\text { Mstaarabu }(\mathrm{N}) \text { persona } \\
\text { civilizada, inteligente }\end{array}$ & $\begin{array}{l}\text { Mozárabe (adj) voz que } \\
\text { designa un cristiano de las } \\
\text { minorías hispánicas que } \\
\text { vivieron en la España } \\
\text { musulmana hasta fines del } \\
\text { siglo XI, conservando su } \\
\text { religión e incluso su } \\
\text { organización eclesiástica y } \\
\text { judicial como también al } \\
\text { individuo de las mismas } \\
\text { comunidades emigrado a } \\
\text { los reinos cristianos del } \\
\text { Norte, llevando consigo } \\
\text { elementos culturales } \\
\text { musulmanes. }\end{array}$ & $\begin{array}{l}\text { /musta'rab/ }(\mathrm{N}) \text { persona } \\
\text { arabizada }\end{array}$ \\
\hline Nabii (N) profeta & $\begin{array}{l}\text { Nabí }(\mathrm{N}) \text { entre los árabes, } \\
\text { profeta }\end{array}$ & /nabî/ (N) profeta \\
\hline Nargisi (N) narciso & $\begin{array}{l}\text { Narciso (N) Planta de la } \\
\text { familia de las amarilidáceas, } \\
\text { que se cultiva en los } \\
\text { jardines por la belleza de } \\
\text { sus flores. Las flores son de } \\
\text { color blanca o amarilla y } \\
\text { olorosas. Préstamo latino, } \\
\text { de origen griego }\end{array}$ & /narwisi/ (N) narciso \\
\hline
\end{tabular}




\begin{tabular}{|c|c|c|}
\hline $\begin{array}{l}\text { Rahisi (adj) fácil, } \\
\text { barato, de bajo precio }\end{array}$ & $\begin{array}{l}\text { Rahez (adj) vil, bajo, } \\
\text { despreciable }\end{array}$ & $\begin{array}{l}\text { /rajîs/ (adj) fácil, barato, de } \\
\text { bajo precio, blando, tierno, } \\
\text { bajo }\end{array}$ \\
\hline $\begin{array}{l}\text { Ramadhan }(\mathrm{N}) \text { mes del } \\
\text { ayuno para los } \\
\text { musulmanes }\end{array}$ & $\begin{array}{l}\text { Ramadán }(\mathrm{N}) \text { mes del ayuno } \\
\text { para los musulmanes }\end{array}$ & $\begin{array}{lll}\text { /ramadân/ } & (\mathrm{N}) \text { mes del } \\
\text { ayuno para } & \text { los } \\
\text { musulmanes } & & \end{array}$ \\
\hline $\begin{array}{l}\text { Robo }(\mathrm{N}) \text { cuarto, la } \\
\text { cuarta parte }\end{array}$ & $\begin{array}{l}\text { Robo }(\mathrm{N}) \text { medida de trigo, } \\
\text { cebada y otros áridos, usada } \\
\text { en Navarra y equivalente a } \\
28 \text { litros y } 13 \text { centilitros }\end{array}$ & $\begin{array}{l}/ \mathrm{rub}^{\prime} /(\mathrm{N}) \text { cuarto, la cuarta } \\
\text { parte }\end{array}$ \\
\hline $\begin{array}{l}\text { Safari (N) viaje, } \\
\text { expedición }\end{array}$ & $\begin{array}{l}\text { Safari }(\mathrm{N}) \text { excursión de caza } \\
\text { mayor, que se realiza en } \\
\text { algunas regiones de África. } \\
\text { Préstamo kiswahili de } \\
\text { origen árabe }\end{array}$ & /safâr/ (N) viaje, expedición \\
\hline $\begin{array}{l}\text { Sala }(\mathrm{N}) \text { oración, } \\
\text { oración } \\
\text { invocación rúrgica, } \\
\text { imploración }\end{array}$ & $\begin{array}{l}\text { Zalá }(\mathrm{N}) \text { oración de los } \\
\text { musulmanes, azalá }\end{array}$ & $\begin{array}{l}\text { /salâ/ (N) oración litúrgica, } \\
\text { invocación ritual, imploración }\end{array}$ \\
\hline $\begin{array}{l}\text { Salaam/salamu }(\mathrm{N}) \\
\text { salutación, saludo, } \\
\text { cumplido }\end{array}$ & $\begin{array}{l}\text { Zalama }(\mathrm{N}) \text { demostración } \\
\text { de cariño afectada }\end{array}$ & $\begin{array}{l}\text { /salâm/ (N) salutación, } \\
\text { saludo, cumplido }\end{array}$ \\
\hline Simsim (N) sésamo & $\begin{array}{l}\text { Sésamo }(\mathrm{N}) \quad \text { planta } \\
\text { pedalácea, de la especie del } \\
\text { ajonjolí y alegría. Préstamo } \\
\text { latino de origen griego }\end{array}$ & /simsim/ (N) sésamo \\
\hline $\begin{array}{l}\text { Sifuri/sufuri (adj) cero, } \\
\text { vacío }\end{array}$ & $\begin{array}{l}\text { Cero (adj) cardinal que } \\
\text { expresa una cantidad nula, } \\
\text { nada, ninguno }\end{array}$ & $\begin{array}{l}\text { /sifr/ (adj) vacío o exento de } \\
\text { cantidad o de número }\end{array}$ \\
\hline Soko $(\mathrm{N})$ mercado & $\begin{array}{l}\text { Zoco }(N) \text { en Marruecos, } \\
\text { mercado, lugar en que se } \\
\text { celebra }\end{array}$ & /sûq/ (N) mercado \\
\hline Sufi (N) lana & $\begin{array}{l}\text { Sufí (adj) sectario o } \\
\text { partidario del sufismo }\end{array}$ & /sûf/ (N) lana \\
\hline
\end{tabular}




\begin{tabular}{|c|c|c|}
\hline Sukari (N) azúcar & $\begin{array}{l}\text { Azúcar (N) sustancia } \\
\text { blanca, cristalizada del } \\
\text { grupo químico de los } \\
\text { hidratos de carbono de } \\
\text { dulce sabor que se extrae de } \\
\text { la caña dulce, de la } \\
\text { remolacha y de otros } \\
\text { vegetales }\end{array}$ & $\begin{array}{l}\text { /as-suqâr/ (N) azúcar. } \\
\text { Préstamo persa, de origen } \\
\text { sanskrito }\end{array}$ \\
\hline $\begin{array}{l}\text { Sultan (N) rey, } \\
\text { gobernador, jefe, } \\
\text { soberano }\end{array}$ & $\begin{array}{l}\text { Sultán }(\mathrm{N}) \text { emperador de los } \\
\text { turcos; príncipe o gobernador } \\
\text { mahometano }\end{array}$ & $\begin{array}{l}\text { /sultân/ }(\mathrm{N}) \text { rey, gobernador } \\
\text { jefe, soberano }\end{array}$ \\
\hline $\begin{array}{l}\text { Sura (N) capítulo; } \\
\text { cualquiera de las } \\
\text { lecciones o capítulos en } \\
\text { que se divide el Corán }\end{array}$ & $\begin{array}{l}\text { Sura }(\mathrm{N}) \text { cualquiera de las } \\
\text { lecciones o capítulos en que } \\
\text { se divide el Corán }\end{array}$ & $\begin{array}{l}\text { /sûra/ (N) cualquiera de las } \\
\text { lecciones o capítulos en que } \\
\text { se divide el Corán }\end{array}$ \\
\hline $\begin{array}{l}\text { Taifa }(\mathrm{N}) \text { nación, raza, } \\
\text { pueblo }\end{array}$ & $\begin{array}{l}\text { Taifa }(\mathrm{N}) \text { cada uno de los } \\
\text { reinos en que se dividió la } \\
\text { España árabe al disolverse el } \\
\text { califato cordobés }\end{array}$ & $\begin{array}{l}\text { /ta'ifa/ (N) grupo, bandería, } \\
\text { facción, pueblo, partido, } \\
\text { denominación }\end{array}$ \\
\hline Udi $(\mathrm{N})$ laúd & $\begin{array}{l}\text { Laúd (N) instrumento } \\
\text { musical que se toca } \\
\text { punteando o hiriendo las } \\
\text { cuerdas: su parte inferior es } \\
\text { cóncava y prominente, } \\
\text { compuesta de muchas } \\
\text { tablillas como costillas }\end{array}$ & /al-'ud/ (N) laúd \\
\hline $\begin{array}{l}\text { Wallahi (Interj.) ¡Por } \\
\text { Dios! }\end{array}$ & $\begin{array}{l}\text { ¡Gualá! (interj.) ant. desus. } \\
\text { Por Dios, por cierto. }\end{array}$ & /wa-llâh/ (Interj.) ipor Dios! \\
\hline Waziri (n) ministro & $\begin{array}{l}\text { Visir }(\mathrm{N}) \text { ministro de un } \\
\text { soberano musulmán }\end{array}$ & /wazîr/ (N) ministro \\
\hline Zafarani (N) azafrán & Zafrán $(\mathrm{N})$ azafrán & /sa'farân/ (N) azafrán \\
\hline $\begin{array}{l}\text { Zaituni/zeituni (N) la } \\
\text { oliva }\end{array}$ & Aceituna (N) la oliva & /as-saitûn/ (N) la oliva \\
\hline
\end{tabular}

